\title{
Harmine specifically inhibits protein kinase DYRK1A and interferes with
} neurite formation

Nora Göckler ${ }^{1}$, Guillermo Jofre ${ }^{2}$, Chrisovalantis Papadopoulos ${ }^{1}$, Ulf Soppa ${ }^{1}$, Francisco J. Tejedor ${ }^{2}$, Walter Becker ${ }^{1 *}$

${ }^{1}$ Institute of Pharmacology and Toxicology, Medical Faculty of the RWTH Aachen University, Wendlingweg 2, 52074 Aachen, Germany

${ }^{2}$ Instituto de Neurociencias, Consejo Superior de Investigaciones Científicas (CSIC) and Universidad Miguel Hernandez, Sant Joan, 03550 Alicante, Spain.

\section{${ }^{*}$ Corresponding author:}

Walter Becker, Institute of Pharmacology and Toxicology, RWTH Aachen University, Wendlingweg 2, 52074 Aachen, Germany

Tel.: +49-241-80-89124

Fax: +49-241-80-82433

Email: wbecker@ukaachen.de

Running title: Harmine, a specific inhibitor of DYRK1A

\begin{abstract}
Abbreviations:
DYRK, dual-specificity tyrosine phosphorylation-regulated kinase; GFP, green fluorescent protein; GST, glutathione S-transferase; MAO, monoamine oxidase; MNB, minibrain kinase; SF3B1, splicing factor 3B1;
\end{abstract}

\section{Keywords}

harmine, kinase inhibitor, DYRK1A, neurite formation, autophosphorylation,

Subdivision: Signal transduction 


\begin{abstract}
DYRK1A is a dual specificity protein kinase that autophosphorylates a conserved tyrosine residue in the activation loop but phosphorylates exogenous substrates only at serine or threonine residues. Tyrosine autophosphorylation of DYRK kinases is a one-off event that takes place during translation and induces the activation of the kinase. Here we characterize the beta-carboline alkaloid harmine as a potent and specific inhibitor of DYRK1A both in vitro and in cultured cells. Comparative in vitroassays of four kinases of the DYRK family showed that harmine inhibited substrate phosphorylation by DYRK1A more potently than the closely related kinase DYRK1B $\left(\mathrm{IC}_{50}\right.$ values of $33 \mathrm{nM}$ vs. $\left.166 \mathrm{nM}\right)$ and the more distant members of the family, DYRK2 and DYRK4 (1.9 $\mu \mathrm{M}$ and $80 \mu \mathrm{M})$. Much higher concentrations of harmine were required to suppress tyrosine autophosphorylation of the translational intermediate of DYRK1A in a bacterial in vitro-translation system $\left(\mathrm{IC}_{50}=1.9 \mu \mathrm{M}\right)$. Importantly, harmine inhibited the phosphorylation of a specific substrate by DYRK1A in cultured cells with a similar potency to that observed in vitro $\left(\mathrm{IC}_{50}=48 \mathrm{nM}\right)$, without negative effects on the viability of the cells. Overexpression of the DYRK1A gene on chromosome 21 has been implicated in the altered neuronal development observed in Down syndrome. Here, we show that harmine interferes with neuritogenesis in cultured hippocampal neurons. In summary, our data show that harmine inhibits DYRK1A substrate phosphorylation with higher potency than tyrosine autophosphorylation, and provide evidence for a role of DYRK1A in the regulation of neurite formation.
\end{abstract}


Given its localization on chromosome 21 within the Down syndrome critical region and the minimal region for partial monosomy 21 , as well as its genetic linkage to microcephaly, the human $D Y R K 1 A$ (dual-specificity tyrosine phosphorylationregulated kinase $1 \mathrm{~A})$ gene has been implicated in the neurodevelopmental alterations associated with these syndromes $[1,2,3,4]$. DYRK1A (also called $M N B)$ is the ortholog of the Drosophila mnb (minibrain) gene that is involved in neurogenesis [5]. Diverse evidence has also related mammalian DYRK1A to neuronal differentiation processes $[6,7,8,9,10,11,12,13]$. Supporting the pathogenetic role of an imbalance in DYRK1A gene dosage, consistent alterations in neurogenesis and neuronal structure were observed in mouse models with a selective gain or partial loss of function of Dyrk1A (as reviewed in ref. [14]).

In addition to its function in neuronal development, recent evidence has also implicated DYRK1A in the pathology of neurodegenerative disorders such as Alzheimer's disease, dementia with Lewy bodies and Parkinson's disease. DYRK1A has been shown to promote the formation of pathophysiological hallmarks of these diseases via direct phosphorylation of their most abundant components, such as tau in neurofibrillary tangles $[11,15,16]$, $\alpha$-synuclein in Lewy bodies [17] and amyloid $\beta$ precursor protein (APP) [18]. In addition, we have recently shown that DYRK1A phosphorylates septin 4 [19], a protein that has been associated with neurofibrillary tangles in Alzheimer's disease and with $\alpha$-synuclein-positive cytoplasmic inclusions in Parkinson disease. Protein levels, as well as the catalytic activity, of DYRK1A are increased in central neurons in Down syndrome and Alzheimer's disease [11,15,20]. These findings raise the possibility that the formation of these protein aggregates in neurodegenerative diseases can be prevented or delayed by pharmacological inhibition of the excessive activity of DYRK1A. 
DYRK1A contains a conserved tyrosine residue in the activation loop of the catalytic domain (Tyr321) whose phosphorylation is required for full catalytic activity [21]. In contrast to related kinases, such as the MAP-kinase family, the activating tyrosine phosphorylation of DYRK family kinases is not catalysed by upstream kinases but occurs through autophosphorylation [21,22]. For the Drosophila kinases dDYRK2 and MNB, this autophosphorylation has been shown to take place during translation [23]. Thus, mature DYRK kinases are incapable of catalyzing their tyrosine autophosphorylation [22,24]. This implies that inhibitors of the one-off autophosphorylation reaction should irreversibly inhibit DYRK kinases. Lochhead et al. [23] have distinguished two classes of DYRK inhibitors, those that target only the mature kinase, and those that also inhibit the tyrosine autophosphorylation of the translational intermediate. Although purvalanol A has been shown to block tyrosine autophosphorylation of dDYRK2 [23], its proposed irreversible effect has not yet come under scrutiny.

Several compounds originally designed to target other protein kinases also inhibit DYRK1A, e.g. the CDK inhibitors roscovitine and purvalanol A [25]. New synthetic DYRK1A inhibitors were rationally developed as potential therapeutic agents to target learning and memory deficits in Down syndrome, but their selectivity has not yet been tested against a broad panel of kinases [26,27]. Two plant compounds, epigallocatechin-gallate (EGCG) and harmine, have been identified as highly specific DYRK inhibitors in the course of systematic surveys of kinase inhibitors [25,28]. EGCG, the major polyphenolic compound of green tea, has been used in studies of DYRK1A [24,29], but its usefulness in cell and animal experiments is compromised by complicated pharmacokinetic properties and poor bioavailability $[30,31]$. Harmine is an alkaloid originally isolated from the South American vine 
Banisteriopsis caapi and has previously been characterized as a potent inhibitor of monoamine oxidase A (MAO-A) [32].

In this study we have determined the potency and specificity of harmine towards DYRK1A compared to other members of the DYRK family and analyzed in vitro and in cultured cells whether harmine discriminates between substrate phosphorylation and tyrosine autophosphorylation of DYRK1A. Finally, we have taken advantage of harmine to assess the possible involvement of DYRK1A in neurite formation using cultured neurons.

\section{Results}

\section{Harmine inhibits DYRK1A more potently than other members of the DYRK family}

The kinase selectivity screen of Bain and colleagues [28] included DYRK1A, DYRK2 and DYRK3 but not DYRK1B or DYRK4. We have therefore compared the specificity of harmine towards DYRK1A and related DYRK-kinases in in vitro kinase assays and determined the $\mathrm{IC}_{50}$ values for recombinant DYRK1A, DYRK1B, DYRK2, DYRK4 and the Drosophila homologue of DYRK1A/DYRK1B, minibrain (MNB). As shown in Fig. $1 \mathrm{C}$, harmine inhibited DYRK1A with the highest potency $\left(\mathrm{IC}_{50}\right.$ value $=$ $33 \mathrm{nM}$ ). Notably, the closely related isoform, DYRK1B (Fig. 1B) was inhibited with approximately 5-fold lower potency than DYRK1A $\left(\mathrm{IC}_{50}=165 \mathrm{nM}\right.$, see Table 1$)$ and approximately similar potency to Drosophila MNB $\left(\mathrm{IC}_{50}=149 \mathrm{nM}\right.$, Fig. 1D), which also exhibits $85 \%$ sequence identity with DYRK $1 \mathrm{~A}$ in the catalytic domain. $I C_{50}$ values for DYRK2 and DYRK4 were found to be more than 10-fold higher ( $2 \mu \mathrm{M}$ and $74 \mu \mathrm{M})$. 


\section{The effects of harmine in cell culture}

We next analyzed the effect of harmine on cell viability, because it has previously been characterized as a cytotoxic agent [33]. Viability assays with HeLa and HEK293 cells showed that harmine displays minimal toxicity at concentrations up to $1 \mu \mathrm{M}$ (Fig. 2A). Thus, concentrations of harmine that cause near complete inhibition of DYRK1A in vitro do not affect cell viability. Similar to the results reported by Song et al. [33], toxic effects were observed at harmine concentrations greater than $3 \mu \mathrm{M}$. Significant reduction of cell viability by high harmine concentrations (10 $\mu \mathrm{M})$ was first detectable after $30 \mathrm{~h}$ (Fig. 2B). Continuous monitoring of cell growth by revealed that inhibitory effects of $3.3 \mu \mathrm{M}$ and $10 \mu \mathrm{M}$ harmine were first detectable after 12-15 h of treatment (Fig. 2C), consistent with the notion of Song et al. [33] that high concentrations of harmine block cell proliferation by inhibiting cyclin dependent kinases.

To examine whether harmine could inhibit DYRK1A activity in cells, we investigated the effect of harmine on the DYRK1A-catalysed phosphorylation of its known substrate, the splicing factor SF3B1. We have previously shown that DYRK1A phosphorylates SF3B1 at Thr434, and that shRNA-mediated knockdown of DYRK1A suppresses the phosphorylation of Thr434 [34]. HeLa cells were transiently transfected with an expression vector encoding a fusion protein of green fluorescent protein (GFP) and the N-terminal part of SF3B1 (amino acids 1-492) and treated with varying concentrations of harmine. Western blot analysis showed that harmine reduced the level of phospho-Thr434 in SF3B1 in a concentration-dependent manner (Fig. 3A). Quantitative evaluation of three independent experiments yielded an $\mathrm{IC}_{50}$ value of $48 \mathrm{nM}$ (Fig. 3B). This experiment shows that harmine is a highly cellpermeant inhibitor of DYRK1A. 


\section{Harmine does not inhibit tyrosine autophosphorylation of DYRK1A in HEK293 cells}

Next, we asked whether harmine could not only inhibit the activity of the mature form of DYRK1A (as in the in vitro assays), but also prevent its activation by tyrosine autophosphorylation. To address this question, we used a HEK293 subline that overexpresses GFP-DYRK1A stably under the control of a doxycyclinregulatable promoter [19]. Immediately after induction with doxycyclin, the cells were (or were not) treated with harmine for $48 \mathrm{~h}$. GFP-DYRK1A was immunoprecipitated and subjected to kinase assays and Western blot analysis (Fig. 4). Harmine was applied at a concentration of $4 \mu \mathrm{M}$, at which concentration the phosphorylation of Thr434 in the endogenous SF3B1 in HEK293 cells was completely blocked (Fig. 4B). In contrast, harmine treatment only modestly inhibited tyrosine phosphorylation of GFP-DYRK1A (Fig. 4A). Furthermore, the catalytic activity of GFP-DYRK1A that was isolated from harmine treated cells did not differ significantly $(p=0.09)$ from that purified from untreated cells (Fig. 4C). This result indicates that harmine does not inhibit the activation of DYRK1A by tyrosine autophosphorylation at a concentration that leads to the complete inhibition of DYRK1A activity towards SF3B1.

\section{The effect of harmine on tyrosine autophosphorylation in vitro}

Lochhead et al. [23] had employed a cell free translation system based on rabbit reticulocyte lysates to determine the differential effects of inhibitors on tyrosine autophosphorylation of Drosophila DYRK2. Our attempts to reproduce this result for mouse DYRK1A failed, probably because the amounts of in vitro-translated protein were too small for the immunochemical detection of phosphotyrosine (data not shown). Much higher amounts of FLAG-DYRK1A were produced when we used 
wheat germ extract for the in vitro-translation, allowing us to determine the phosphotyrosine content by Western blot analysis (Fig. 5A). Harmine was applied at a concentration of $1 \mu \mathrm{M}$, which inhibited the catalytic activity of DYRK1A by more than $90 \%$, both in vitro (Fig. 1) and in HeLa cells (Fig. 3). It was also applied at $10 \mu \mathrm{M}$ to achieve maximal inhibition. For comparison, the effect of purvalanol A was analyzed in parallel because this inhibitor was shown by Lochhead et al. [23] to inhibit the tyrosine autophosphorylation of Drosophila DYRK2 at a concentration of $50 \mu \mathrm{M}$. Both harmine and purvalanol A caused a reduction of immunoreactive phosphotyrosine in FLAG-DYRK1A, although tyrosine autophosphorylation was only partially blocked even at the higher concentrations of the inhibitors (Fig. 5B). The catalytic activity of FLAG-DYRK1A after purification from the reaction mixture was unaffected by the preceding treatment with harmine and it was marginally reduced after treatment with purvalanol A (Fig. 5C).

\section{In vitro translation in a bacterial expression system}

In vitro translation in eukaryotic cell-free systems allowed us to study the effect of harmine on the co-translational tyrosine autophosphorylation of the DYRK kinases. However, such reaction mixes are still highly complex systems containing other protein kinases and proteins that may indirectly affect the enzymatic properties of DYRK1A. Therefore, we took advantage of the newly developed PURExpress in vitro-translation system, which relies on well-defined and purified components from $E$. coli to reconstitute cell-free translation [35]. For these experiments, we generated a bacterial expression construct that produced only the catalytic domain of DYRK1A (DYRK1Acat), and thus lacked most of the tyrosines in the N-terminal domain. In particular, DYRK1Acat does not include Tyr111, which we have previously identified as a major autophosphorylation site of recombinant DYRK1A in E. coli [21]. First, we 
determined the time course of DYRK1Acat tyrosine autophosphorylation. Recombinant His $_{6}$-SF3B1-NT was added as a substrate for DYRK1A in order to assess whether catalytically active DYRK1Acat was produced by the bacterial in vitro-translation system. As shown in Fig. 6A, pThr434 phosphorylation was detectable after $30 \mathrm{~min}$, whereas no phosphorylation of SF3B1 took place in control reactions expressing dihydrofolate reductase (data not shown). Tyrosine phosphorylation of DYRK1Acat was first detectable after $60 \mathrm{~min}$ and increased further over time. These results confirm that the DYRK1Acat construct generated by the cell-free bacterial expression system is capable both of tyrosine autophosphorylation and substrate phosphorylation much like the native protein. The fact that substrate phosphorylation was detected prior to autophosphorylation may be attributable to the differing sensitivities of the phospho-specific antibodies. Next, we added harmine to the in-vitro transcription/translation reaction in order to analyze its effect on tyrosine autophosphorylation. As shown in Fig. 6B, harmine concentrationdependently inhibited the tyrosine autophosphorylation of DYRK1Acat with an IC $\mathrm{C}_{50}$ of $1.80 \mu \mathrm{M}$.

\section{The effect of harmine on neurite formation in hippocampal neurons}

To assess the physiological consequences of the inhibition of the protein kinase activity of DYRK1A by harmine in the nervous system, we set out to test its effects on neuronal differentiation, a complex sequence of processes in which MNB and DYRK1A have been previously implicated (see Introduction). Several observations point to a role of DYRK1A in neuritogenesis, an early differentiation process, although no direct evidence has been so far provided (see Discussion for details). Accordingly, we decided to use harmine to assess this new possible function 
of DYRK1A. Thus, we focus our analysis on the effects of harmine on neurite formation using cultured hippocampal neurons prepared from mouse embryos.

First, we tested the consequences of harmine treatment on the viability of these cells. In agreement with what we found in the cell lines, we did not detect any apparent negative effect within 5 days of culture at concentrations up to $2 \mu \mathrm{M}$ (not shown). In order to ensure that only stably growing neurites but not transient filopodia were considered in our analysis, cells were fixed in cold paraformaldehyde and their morphology (i.e. number of growing neurites) was analyzed by anti- $\beta 3$ tubulin (TUJ1) antiserum immunostaining. As shown in Fig. 7A, hippocampal neurons that were treated with harmine for 3 days at a concentration of $1.6 \mu \mathrm{M}$ displayed a significant reduction in the number of neurites compared to untreated controls. For instance, harmine shifted the median number of neurites of these neurons from four to three (Fig. 8A, B, C). This overall decrease in the number of neurites was statistically significant as determined by a paired Student's $t$ test of the mean value of the number of neurites per neuron from three independent experiments $(p=0.021)$. Nevertheless, we noticed that the inhibitory effect of harmine was statistically significant only for neurons with 4 or less neurites when data of control and harminetreated neurons were paired for independent Student's $t$ test analysis (Fig. 8A). This may suggest that harmine was less effective in neurons that were already developing neurites at the time when harmine was added to the culture. 


\section{Discussion}

In this study we have determined the inhibitory potency of the $\beta$-carboline alkaloid harmine towards DYRK1A and the closely related kinases DYRK1B, DYRK2 DYRK4 and Drosophila MNB. Furthermore, we demonstrate that harmine differentially inhibits substrate phosphorylation by the mature DYRK1A protein and tyrosine autophosphorylation of the translational intermediate of DYRK1A. Finally, we take advantage of harmine to provide evidence for a function of DYRK1A in neurite formation.

Specificity is a serious concern whenever inhibitors are used to dissect the biological functions of a given protein kinase, as unwanted effects on other kinases may lead to erroneous conclusions. Here we show that harmine displays exceptional specificity towards DYRK1A even in comparison with the other members of the DYRK family. The $\mathrm{IC}_{50}$-value for DYRK2 $(2 \mu \mathrm{M})$ was about 50 -fold higher than for DYRK1A (33 nM), whereas DYRK4 was largely resistant to harmine $\left(\mathrm{IC}_{50}>50 \mu \mathrm{M}\right)$. Our result for DYRK2 matches quite well with the published data of Bain et al. [28] who measured $\mathrm{IC}_{50}$ values of $0.9 \mu \mathrm{M}$ (at $50 \mu \mathrm{M}$ ATP) for DYRK2 and $0.8 \mu \mathrm{M}$ for its closest neighbor, DYRK3. Five-fold higher concentrations of harmine were required for the inhibition of DYRK1B or MNB than for DYRK1A (Table 1), although these kinases exhibit $85 \%$ sequence identity with DYRK1A in the catalytic domain.

Although important, this difference between the inhibitory potencies of harmine towards DYRK1A and DYRK1B is too small to fully discriminate pharmacologically between the cellular effects of these kinases. Nevertheless, at a concentration of 1 $\mu \mathrm{M}$, harmine inhibits DYRK1A, DYRK1B by $>90 \%$ but only marginally affects the activities of other DYRK family members. Side effects caused by inhibition of other protein kinases are unlikely because Bain et al. [28] reported modest inhibition by harmine only for CK1 $\left(\mathrm{IC}_{50}=1.5 \mu \mathrm{M}\right)$ and PIM3 $\left(\mathrm{IC}_{50}=4.3 \mu \mathrm{M}\right)$, among 69 kinases 
tested. Actually, harmine has been applied at concentrations of $1 \mu \mathrm{M}$ in recent studies to confirm the proposed role of DYRK1A in the phosphorylation of caspase 9 [36,37] and septin 4 [19] and in the negative regulation of NFAT signaling in cardiomyocytes [38].

We measured an $\mathrm{IC}_{50}$ of $33 \mathrm{nM}$ for the inhibition of DYRK1A by harmine in vitro, which is in reasonable agreement with the value obtained by Bain et al. [28] (80 $\mathrm{nM})$. This is an exceptionally high potency for a low molecular weight compound (212 Da) that has not been optimized for its affinity. Importantly, harmine inhibited endogenous DYRK1A in HeLa cells with a similarly high potency $\left(\mathrm{IC}_{50}=48 \mathrm{nM}\right)$, which is prerequisite for use of the inhibitor in cell culture experiments. However, harmine inhibits monoamine oxidase $A$ with an $\mathrm{IC}_{50}$ of $5 \mathrm{nM}$ [32], which precludes the inhibition of DYRK1A in animal experiments without simultaneously blocking MAO-A. On the other hand, the antidiabetic effect of harmine as an inducer of PPAR $\gamma$ expression required concentrations higher than $1 \mu \mathrm{M}$ [39]. Hence, this effect of harmine is necessarily accompanied by a near-maximal inhibition of DYRK $1 A$. Interestingly, mean peak plasma levels of $0.54 \mu \mathrm{M}$ harmine have been determined in volunteers after ingestion of the hallucinogenic hoasca beverage within a ceremonial context [40]. Hoasca is a decoction of Banisteriopsis caapi and dimethyltryptaminecontaining plants, and is regularly used in shamanic rituals and South American sects for its visionary effects. Thus, regular users of hoasca are repeatedly exposed to levels of harmine that cause a substantial inhibition of DYRK1A. Similar doses of harmine to those ingested by hoasca users (about $250 \mathrm{mg}$, [40] were used at the end of the 1920s for the treatment of postencephalitic Parkinsonism [41].

A point of particular interest to note in respect of the inhibitors of DYRK kinases is the potential capacity to block autophosphorylation of the critical activationloop tyrosine, which is expected to irreversibly inhibit the kinase [23]. We found no 
reduction of phosphotyrosine in GFP-DYRK1A that was isolated from harminetreated HEK293 cells, and the catalytic activity was unaltered when compared to GFP-DYRK1A from untreated cells (Fig. 4). In the same cells, phosphorylation of SF3B1 at Thr434 was completely blocked by treatment with harmine. Of note, DYRK1A autophosphorylation at Ser520 in HEK293 cells was almost completely inhibited by harmine treatment at a concentration of $1 \mu \mathrm{M}$ [36]. Taken together, these results indicate that harmine inhibits both substrate phosphorylation and serine autophosphorylation of mature DYRK1A but not tyrosine autophosphorylation of the translational intermediate.

The in vitro-translation of DYRK1A in wheat germ extract allowed us to test higher concentrations of harmine $(10 \mu \mathrm{M})$ that are toxic for cells. The presence of harmine during translation caused a concentration-dependent inhibition of tyrosine autophosphorylation of DYRK1A, although the inhibitory effect did not reach statistical significance and was much less potent than the inhibition of substrate phosphorylation. In contrast to our results, Seifert et al. [37] reported a concentrationdependent reduction of immunoreactive phosphotyrosine of in vitro-translated DYRK1A with complete inhibition at $1 \mu \mathrm{M}$ harmine. These seemingly divergent results may be attributable to the different in vitro-translation systems used (wheat germ extract vs. rabbit reticulocyte lysate), different concentrations of ATP used in the reactions, or the use of different phosphotyrosine-specific antibodies. Different monoclonal antibodies may recognize different phosphotyrosine residues, and the Phosphosite database (www.phosphosite.org) lists seven phosphorylated tyrosine residues for DYRK1A, most of which are localized in the N-terminal domain.

We consider the results obtained with the PURExpress system to be the most informative concerning the inhibitory effect of harmine on tyrosine autophosphorylation. This translation system is reconstituted from isolated $E$. coli 
ribosomes and purified recombinant proteins (including aminoacyl-tRNA synthetases, translation initiation, elongation and release factors) and is not prone to the effects of undefined proteins in the reaction [35]. Notably, tyrosine autophosphorylation of DYRK1Acat in this system demonstrates that this reaction is an intrinsic capacity of the catalytic domain of DYRK1A and does not require the presence of molecular chaperones. About 50-fold higher concentrations of harmine were required to inhibit the tyrosine autophosphorylation of the translational intermediate DYRK1A $\left(I_{50}=\right.$ $1.8 \mu \mathrm{M})$ than the phosphorylation of DYRKtide by the mature DYRK1A $\left(\mathrm{IC}_{50}=0.033\right.$ $\mu \mathrm{M})$. This quantitative analysis confirms and refines the qualitative finding that tyrosine autophosphorylation of DYRK kinases differs from the canonical substrate phosphorylation in the sensitivity to small-molecule inhibitors [23].

Lochhead et al. [23] identified purvalanol A as the paradigmatic inhibitor of cotranslational tyrosine autophosphorylation of Drosophila dDYRK2, using rabbit reticulocyte lysate. Although no quantitative evaluation was provided, the published data suggest that purvalanol A inhibited the phosphorylation of a peptide substrate by dDYRK2 with a similar $\mathrm{IC}_{50}$ as for the tyrosine autophosphorylation. In contrast, 50 $\mu \mathrm{M}$ purvalanol $\mathrm{A}$ only partially blocked tyrosine autophosphorylation of mouse DYRK1A (Fig. 5B), though purvalanol $A$ inhibited the in vitro-phosphorylation of DYRKtide by DYRK1A with an $\mathrm{IC}_{50}$ of $300 \mathrm{nM}$ (data not shown). The differential sensitivity of mammalian DYRK1A and dDYRK2 (the ortholog of mammalian DYRK4) to purvalanol $\mathrm{A}$ is not surprising, given that these kinases belong to distinct branches of the DYRK family of protein kinases (Fig. 1B).

Extensive evidence relates mammalian DYRK1A and its orthologues (Drosophila MNB, chicken MNB) to neuronal differentiation processes. In particular, the fact the MNB/DYRK1A is localized in the growing dendritic tree of diverse vertebrate central neurons $[7,12]$ strongly suggests a role in the regulation of dendrite 
growth. This function is supported by evidence that cortical pyramidal neurons of Dyrk $1 A^{+/-}$mouse exhibit smaller dendritic arbors than those of wild type mice [8] and conversely, hippocampal and cortical neurons of transgenic mice that overexpress Dyrk1A exhibit increased size [42]. Nevertheless, there are also some indications that MNB/DYRK1A might be involved in earlier steps of neuronal differentiation. For instance, upregulation of MNB/DYRK1A expression has been shown to precede the onset of dendrite formation in several neuronal populations $[7,12]$. It has also been reported that DYRK1A is markedly upregulated during the bFGF-induced differentiation of a hippocampal progenitor cell line and that blockade of this upregulation significantly inhibits neurite formation [6]. Moreover, a recent RNAi screen in Drosophila identified MNB as a regulator of cell protrusions in cell lines derived from the central nervous system [43]. Together, these data point to the possible involvement of DYRK1A on the regulation of neurite formation. Accordingly, we have here shown that harmine inhibited neuritogenesis in cultured hippocampal neurons. Thus, our results provide the first evidence for a role of DYRK1A on neurite formation in bona fide neurons. Future research should shed light upon the molecular mechanisms underlying this novel DYRK1A function.

In conclusion, the present data show that harmine is a potent and selective inhibitor that can be used as a pharmacological tool to interfere with functions of the protein kinase DYRK1A in cultured neurons. Although the exploration of its therapeutic options using Down syndrome animal models are in principle compromised by its MAO inhibitory effect, harmine may serve as a lead compound to develop a novel DYRK1A inhibitor devoid of MAO inhibiting activity. 


\section{Materials and Methods}

\section{Cell culture and transfection}

HeLa cells were cultured in RPMI-1640 medium (PAA Laboratories, Pasching, Austria) supplemented with $10 \%$ fetal calf serum (PAA) at $37^{\circ} \mathrm{C}$ in a humidified $5 \%$ $\mathrm{CO}_{2}$ atmosphere. For controlled overexpression of DYRK1A, we used a stably transfected HEK293 cell clone expressing GFP-DYRK1A under the control of a tetracycline-regulated promoter (HEK-tetGFP-DYRK1A) [19]. HEK293 cells were maintained in DMEM High Glucose (4.5 mg/l) (PAA) supplemented with $10 \%$ fetal calf serum. Expression of GFP-DYRK1A was induced with $2 \mu \mathrm{g} / \mathrm{ml}$ doxycycline.

\section{Inhibitors}

Harmine (No. 51400, Fluka, Buchs, Switzerland) was dissolved in ethanol under constant agitation at room temperature to generate a $10 \mathrm{mM}$ solution which was then diluted to a concentration of $0.5 \mathrm{mM}$ with $50 \%(\mathrm{v} / \mathrm{v})$ ethanol. This stock solution was further diluted to the working concentrations with water for in vitro-experiments or with culture medium for the treatment of cultured cells. Purvalanol A (Alexis Biochemicals, Lausen, Switzerland) was dissolved in DMSO to produce a $30 \mathrm{mM}$ solution. Further dilutions for in vitro experiments were also made in DMSO.

\section{Antibodies}

The rabbit antibody for the specific detection of phosphorylated Thr434 in SF3B1 (pThr434) has been described previously [34]. Sheep anti-DYRK1A antibody raised against bacterially expressed GST-DYRK1A- $\Delta \mathrm{C}$ was kindly provided by Philip Cohen (MRC Protein Phosphorylation Unit, Dundee, Scotland, UK). The following antibodies were purchased from commercial sources: mouse monoclonal pan-specific 
SF3B1/SAP155 antibody (MBL, Nagoya, Japan) and anti phosphotyrosine antibody (PY99, Santa Cruz Biotechnology, Santa Cruz, CA), rabbit anti-DYRK1A (Cell Signaling Technology, Beverley, MA) and anti-GFP-antibody (Molecular Probes, Eugene, OR; for immunoprecipitation), and goat GFP-specific antibody (Rockland, Gilbertsville, PA) for immunodetection on Western blots)

\section{Bacterial expression of recombinant proteins}

Plasmids for the bacterial expression of glutathione S-transferase-(GST-)DYRK1A$\Delta$ C, GST-DYRK1B-p69, and GST-DYRK2 have been described previously $[21,44,45]$ (UniProt acc. Nos. Q63470, Q9Y463, Q92630). The Drosophila minibrain kinase $(\mathrm{MNB})(\underline{\mathrm{P} 49657})$ was expressed as a fusion protein with maltose binding protein $(\mathrm{MBP})$ [45]. GST and MBP fusion proteins were expressed in E. coli and affinity purified using glutathione Sepharose 4B (Amersham Bioscience, Piscataway, NJ) or amylose agarose (New England Biolabs, Beverley, MA). GST-DYRK4 (Q9NR20) expressed from insect cells was obtained commercially (lot 37361G, Invitrogen, Carlsbad, CA). For all DYRK kinases, one unit of kinase activity was defined as the amount of enzyme that catalyzed the phosphorylation of $1 \mathrm{nmol}$ DYRKtide per min at $30^{\circ} \mathrm{C}$. His $_{6}$-tagged SF3B1-NT was prepared as described previously [34].

\section{In vitro protein kinase assays}

Assays were performed in reaction mixtures of $12 \mu \mathrm{l}$ at $30^{\circ} \mathrm{C}$ with 8 to 10 different harmine concentrations. Recombinant kinases were added at sufficient concentrations to obtain activities between 0.4 to $5 \mathrm{mU}$ per $12 \mu \mathrm{l}$. The reaction was incubated with $100 \mu \mathrm{M}$ ATP, $100 \mu \mathrm{M}$ DYRKtide, and $0.6 \mu \mathrm{Ci}\left[\mathrm{Y}^{-33} \mathrm{P}\right]-\mathrm{ATP}$ in kinase buffer (25 mM Hepes, $\mathrm{pH} 7.0,5 \mathrm{mM} \mathrm{MgCl}_{2}, 0.5 \mathrm{mM}$ dithiothreitol) for $5 \mathrm{~min}$ at $30^{\circ} \mathrm{C}$. The incorporation of ${ }^{33} \mathrm{P}$ into DYRKtide was determined in triplicate by dotting $3 \mu \mathrm{l}-$ 
aliquots of the reaction mixture onto $0.5 \times 3.0 \mathrm{~cm}$ pieces of phosphocellulose $\mathrm{P}-81$ (Whatman, Maidstone, UK), followed by washing in 5\% phosphoric acid (10 times for 10 minutes each time), and subsequent liquid scintillation counting.

\section{Viability assay}

Effects of inhibitors on cell proliferation and viability were determined with a tetrazolium salt-based assay (WST-1, Quick Cell Proliferation Assay Kit, Biovision, Mountain View, CA). HeLa or HEK293 cells were seeded at a density of 5000 cells/well on 96-well plates. After overnight culture, serial dilutions of harmine in culture medium were applied to the wells (as triplicate samples) and the cells were cultured for $56 \mathrm{~h}$ without changing the medium, before the WST-1 assay was performed in accordance with the manufacturer's instructions. In the time course experiment, harmine was added $10 \mathrm{~h}, 30 \mathrm{~h}$ or $54 \mathrm{~h}$ before addition of WST-1.

\section{Real-time cell-electrode impedance measurements}

We used the xCELLigence System (Roche Diagnostics, Penzberg, Germany) for real-time monitoring of harmine cytotoxicity. Two hundred microliters of growth medium were added to the wells of an E-plate for background measurements. HeLa cells were seeded in triplicate wells at a number of 3,000 and 5,000 cells/well in 200 $\mu \mathrm{l}$. After 24 hours, $100 \mu \mathrm{l}$ of the medium was removed, harmine was added to the respective wells in a volume of $100 \mu \mathrm{l}$ of fresh medium The continuous impedance measurement was recorded and converted to a cell index. Results were analyzed using RTCA Software 1.1 (Roche Diagnostics).

\section{Assay of SF3B1 phosphorylation by DYRK1A in HeLa cells}


HeLa cells were seeded at 80,000 cells/well in 6-well culture plates. After overnight culture, the cells were transfected with the pEGFP-SF3B1-NT plasmid $(0.5 \mu \mathrm{g}$ DNA/well, [34] using the transfection reagent FuGENE 6 (Roche Molecular Biochemicals, Mannheim, Germany). Two hours after transfection, the cells were treated with harmine at variable concentrations $(0.01-1 \mu \mathrm{M})$. Two days after transfection, the cells were lysed with $150 \mu$ l boiling SDS-buffer (20 mM Tris, pH 7.4; $1 \%$ SDS), denatured for 5 minutes at $96^{\circ} \mathrm{C}$ and sonicated for $30 \mathrm{~s}$. The phosphorylation of Thr434 was assessed by Western blot analysis using a rabbit antibody specific for phosphorylated Thr434 in SF3B1 (pThr434) [34]. The Western blots were developed using horseradish peroxidase-coupled secondary antibodies and chemiluminescence detection. The immunoreactivity was quantitated with a LAS3000 CCD imaging system and the AIDA Image Analyzer 5.0 program (Raytest, Straubenhardt, Germany). The values were normalized to GFP-SF3B1-NT expression levels as determined with a pan-specific antibody (anti-SF3B1/SAP155).

\section{Harmine treatment of cultured hippocampal neurons}

Cultures of embryonic mouse hippocampal cells were prepared following standard protocols [46]. In brief, hippocampi from E18 mouse embryos were finely dissected in Hank's Balanced Salt Solution (HBSS). After a mild and short incubation with trypsin in HBSS, the cells were dispersed in DMEM (Invitrogen) medium supplemented with $10 \%$ fetal bovine serum and antibiotics (penicillin and streptomycin). After counting and a viability test employing trypan blue, the cells were plated on poly-L-lysine coated $12 \mathrm{~mm}$ coverslips at a density of 25,000 viable cells $/ \mathrm{cm}^{2}$. After $3 \mathrm{~h}$, nonattached cells were removed by washing and the media was changed to Neurobasal medium (Invitrogen) supplemented with 2\% B27, 2 mM Glutamax plus antibiotics in the presence or absence of harmine. The cells were grown for 3 days in 24-well 
plates. After a brief wash with PBS, the cells were fixed with cold $4 \%$ paraformaldehyde in PBS for $1 \mathrm{~h}$ and washed with PBS. Immunocytochemical staining of the cells was carried out following standard protocols using anti- $\beta 3$ tubulin antiserum (TUJ1, Covance) followed by biotinylated anti-Mouse IgG secondary antiserum and streptavidin-coupled horseradish peroxidase (ABC kit, Vector labs, Burlingame, CA). The cells were observed under the microscope and the number of neurites were counted for a minimum of 100 isolated cells per coverslip. The criteria for a neurite to be counted were to be labelled with TUJ1, to be longer than approximately $10 \mu \mathrm{m}$, and to have a growth cone.

\section{Immunocomplex kinase assay of GFP-DYRK1A and analysis of tyrosine phosphorylation}

HEK-tetGFP-DYRK1A cells were seeded onto $10-\mathrm{cm}$ plates. Two hours after seeding, expression of GFP-DYRK1A was induced by adding $2 \mu \mathrm{M}$ doxycycline, and the cells were then treated with $0.5-4 \mu \mathrm{M}$ harmine. Two days later, cells were lysed under non-denaturating conditions using $1 \mathrm{ml}$ of native lysis buffer per plate $(50 \mathrm{mM}$ Hepes pH 7.4, $150 \mathrm{mM} \mathrm{NaCl}, 25 \mathrm{mM}$ NaF, 2 mM EDTA, $30 \mathrm{mM}$ sodium pyrophosphate, $0.5 \%$ Igepal CA-630 (Sigma), $1 \mathrm{mM}$ sodium vanadate, $10 \mu \mathrm{g} / \mathrm{ml}$ pepstatin, $10 \mu \mathrm{g} / \mathrm{ml}$ leupeptin, $1 \mathrm{mM}$ PMSF, $10 \mu \mathrm{g} / \mathrm{ml}$ aprotinin) on ice. The samples were spun down for 5 minutes, and $18 \mu \mathrm{l}$ aliquots of the supernatants were taken separately for Western blot analysis. The remaining supernatants were incubated with $2 \mu \mathrm{l}$ of rabbit anti-GFP-antibody (Molecular Probes, Eugene, OR) at $4^{\circ} \mathrm{C}$ for one hour before the immuncomplexes were captured using EZview Red Protein G Affinity Gel (Sigma) at $4^{\circ} \mathrm{C}$ over-night.

After washing the agarose beads twice with washing buffer containing Igepal CA-630 (50 mM Tris- $\mathrm{HCl} \mathrm{pH}$ 7.5, $150 \mathrm{mM} \mathrm{NaCl}, 2 \mathrm{mM}$ EDTA, 0.1\% Igepal), twice with 
washing buffer without Igepal and once with kinase buffer, GFP-DYRK1A was assayed in vitro for kinase activity. The assays were carried out at $30^{\circ} \mathrm{C}$ for $30 \mathrm{~min}$ in a total reaction volume of $30 \mu \mathrm{l}$ as described above, except that here we used a concentration of $10 \mu \mathrm{M}$ ATP. After washing the immunoprecipitates with lgepal-free washing buffer, the bound proteins were eluted with sample buffer, separated by SDS-PAGE (8\%) and blotted onto nitrocellulose membranes. The membranes were subjected to Western blot analysis as indicated in the figure legends.

\section{In vitro translation of DYRK1A}

An expression plasmid for FLAG-tagged mouse DYRK1A with a T3 promotor sequence upstream of the open reading frame (pCMV-Tag2A-FLAG-DYRK1A) was kindly provided by Beat Lutz (Johannes Gutenberg Universität Mainz, Germany). Capped mRNA was obtained by in vitro transcription of $1 \mu \mathrm{g}$ of the linearised plasmid (KspAI) using the mMESSAGE mMACHINE High Yield Capped RNA transcription kit (Ambion, Darmstadt, Germany).

In vitro translations with Wheat Germ Extract Plus (Promega) were performed according to the manufacturer's instructions in total reaction volumes of $50 \mu \mathrm{l}$, using $2 \mu \mathrm{g}$ of RNA and $1 \mu \mathrm{l}$ of the inhibitor. After incubation for $2 \mathrm{~h}$ at $25^{\circ} \mathrm{C}, 500 \mu \mathrm{l}$ of the lysis buffer was added to stop the reaction. The samples were immunoprecipitated overnight with $20 \mu \mathrm{l}$ of anti-FLAG M1 agarose affinity resin (Sigma, Taufkirchen, Germany) at $4^{\circ} \mathrm{C}$ and analysed by immunocomplex kinase assay and Western blot analysis. The kinase activities were normalised to the amount of FLAG-DYRK1A as determined via Western blotting.

The PURExpress kit (New England Biolabs, Ipswich, MA) was employed for coupled in vitro transcription/translation experiments in an E. coli-derived system. For these experiments we constructed an expression vector, pET28a-DYRK1Acat, to 
produce a deletion construct of rat DYRK1A that lacks both the non-catalytic $\mathrm{N}$ - and C-terminal domains of DYRK1A (bases 532-1626 of X79769, encoding amino acids $135-499$ of DYRK1A). For the time course (Fig. 6 A), a $35-\mu$ reaction containing 350 ng of pET28a-DYRK1Acat was supplemented with $2.3 \mu \mathrm{g} \mathrm{SF3B1-NT-His_{6 }}$ [31](de Graaf et al., 2006) as a substrate for DYRK1A and $4 \mu \mathrm{l}$ aliquots were taken and stopped by the addition of EDTA at different time points. To test the effect of harmine, reaction mixes (with final volumes of $8 \mu \mathrm{l}$ ) contained $10 \mathrm{ng} / \mu \mathrm{l}$ of the expression plasmid and were incubated for $2 \mathrm{~h}$ at $30^{\circ} \mathrm{C}$ unless otherwise indicated. After addition of gel loading buffer, the samples were incubated at $96^{\circ} \mathrm{C}$ for $5 \mathrm{~min}$ and Western blotted.

\section{Analysis of quantitative data}

The GraphPad Prism 5.0 program (GraphPad Software, La Jolla, CA) was used for curve fitting by nonlinear regression and statistical analysis. The data generated in in vitro kinase assays were fitted to a one-site inhibition model (to a "dose-response curve - inhibition") with a Hill slope of -1 or a variable Hill slope $\left(Y=100 /\left(1+10^{\wedge}((X-\right.\right.$ LogIC50))); or for variable slope: $Y=100 /\left(1+10^{\wedge}\left((\log \mid C 50-X)^{\star} H\right.\right.$ HillSlope $\left.\left.\left.)\right)\right)\right)$. For each data set, the model with the best fit was determined with the extra sum of squares $F$ test $(p<0.05)$. For quantitative evaluation of the HeLa cell experiment (Fig. 3), band intensities were fitted to a "dose-response curve - inhibition" with a Hill slope of -1 .

\section{Acknowledgements:}

We thank Simone Bamberg-Lemper and Esther Llorens for excellent technical assistance, Mariola Rodríguez-Chacon and Ana V Paternain for the help in setting up 
neuronal cultures and Marco Schlepütz for patient and knowledgeable IT support. We are grateful to Jan Sitz and Beat Lutz for providing the FLAG-DYRK1A clone. This work was supported by the Deutsche Forschungsgemeinschaft [Grant BE 1967/2-1] to WB, a grant from the "Ministerio de Ciencia e Innovacion" to FJT, and a grant from the Foundation Jerome LeJeune to FJT and WB. GJ was recipient of a Santiago Grisolia Fellowship from the Generalitat Valenciana. 


\section{References}

1 Arron JR, Winslow MM, Polleri A, Chang CP, Wu H, Gao X, Neilson JR, Chen L, Heit JJ, Kim SK, Yamasaki N, Miyakawa T, Francke U, Graef IA \& Crabtree GR (2006) NFAT dysregulation by increased dosage of DSCR1 and DYRK1A on chromosome 21. Nature, 441, 595-600.

2 Canzonetta C, Mulligan C, Deutsch S, Ruf S, O'Doherty A, Lyle R, Borel C, Lin-Marq N, Delom F, Groet J, Schnappauf F, De VS, Averill S, Priestley JV, Martin JE, Shipley J, Denyer G, Epstein CJ, Fillat C, Estivill X, Tybulewicz VL, Fisher EM, Antonarakis SE \& Nizetic D (2008) DYRK1A-dosage imbalance perturbs NRSF/REST levels, deregulating pluripotency and embryonic stem cell fate in Down syndrome. Am. J. Hum. Genet., 83, 388-400.

3 Hämmerle B, Elizalde C, Galceran J, Becker W \& Tejedor FJ (2003) The MNB/DYRK1A protein kinase: neurobiological functions and Down syndrome implications. J. Neural Transm. Suppl, 129-137.

4 Møller RS, Kubart S, Hoeltzenbein M, Heye B, Vogel I, Hansen CP, Menzel C, Ullmann R, Tommerup N, Ropers HH, Tumer Z \& Kalscheuer VM (2008) Truncation of the Down syndrome candidate gene DYRK1A in two unrelated patients with microcephaly. Am. J. Hum. Genet., 82, 1165-1170.

5 Tejedor F, Zhu XR, Kaltenbach E, Ackermann A, Baumann A, Canal I, Heisenberg M, Fischbach KF \& Pongs O (1995) minibrain: a new protein kinase family involved in postembryonic neurogenesis in Drosophila. Neuron, 14, 287-301

6 Yang EJ, Ahn YS \& Chung KC (2001) Protein kinase Dyrk1 activates cAMP response element-binding protein during neuronal differentiation in hippocampal progenitor cells. J. Biol. Chem., 276, 39819-39824.

7 Hämmerle B, Carnicero A, Elizalde C, Ceron J, Martinez S \& Tejedor FJ (2003) Expression patterns and subcellular localization of the Down syndrome candidate protein MNB/DYRK1A suggest a role in late neuronal differentiation. Eur. J. Neurosci., 17, 2277-2286.

8 Benavides-Piccione R, Dierssen M, Ballesteros-Yanez I, Martinez de LM, Arbones ML, Fotaki V, DeFelipe J \& Elston GN (2005) Alterations in the phenotype of neocortical pyramidal cells in the Dyrk1A+/- mouse. Neurobiol. Dis., 20, 115-122.

9 Kelly PA \& Rahmani Z (2005) DYRK1A enhances the mitogen-activated protein kinase cascade in PC12 cells by forming a complex with Ras, B-Raf, and MEK1. Mol. Biol. Cell, 16, 3562-3573.

10 Park J, Yang EJ, Yoon JH \& Chung KC (2007) Dyrk1A overexpression in immortalized hippocampal cells produces the neuropathological features of Down syndrome. Mol. Cell Neurosci., 36, 270-279.

11 Liu F, Liang Z, Wegiel J, Hwang YW, lqbal K, Grundke-lqbal I, Ramakrishna N \& Gong CX (2008) Overexpression of Dyrk1A contributes to neurofibrillary degeneration in Down syndrome. FASEB J., 22, 3224-3233.

12 Hämmerle B, Elizalde C \& Tejedor FJ (2008) The spatio-temporal and subcellular expression of the candidate Down syndrome gene Mnb/Dyrk1A in the developing mouse brain suggests distinct sequential roles in neuronal development. Eur. J. Neurosci., 27, 1061-1074.

13 Lepagnol-Bestel AM, Zvara A, Maussion G, Quignon F, Ngimbous B, Ramoz N, Imbeaud S, Loe-Mie Y, Benihoud K, Agier N, Salin PA, Cardona A, Khung-Savatovsky S, Kallunki P, Delabar JM, Puskas LG, Delacroix H, Aggerbeck L, Delezoide AL, Delattre O, Gorwood P, Moalic JM \& Simonneau M (2009) DYRK1A interacts with the REST/NRSF-SWI/SNF chromatin remodelling complex to deregulate gene clusters involved in the neuronal phenotypic traits of Down syndrome. Hum. Mol. Genet.

14 Dierssen M \& de Lagran MM (2006) DYRK1A (dual-specificity tyrosine-phosphorylated and -regulated kinase $1 \mathrm{~A}$ ): a gene with dosage effect during development and neurogenesis. ScientificWorldJournal., 6, 1911-1922. 
15 Ferrer I, Barrachina M, Puig B, Martinez de LM, Marti E, Avila J \& Dierssen M (2005) Constitutive Dyrk1A is abnormally expressed in Alzheimer disease, Down syndrome, Pick disease, and related transgenic models. Neurobiol. Dis., 20, 392-400.

16 Ryoo SR, Jeong HK, Radnaabazar C, Yoo JJ, Cho HJ, Lee HW, Kim IS, Cheon YH, Ahn YS, Chung SH \& Song WJ (2007) DYRK1A-mediated hyperphosphorylation of Tau. A functional link between Down syndrome and Alzheimer disease. J. Biol. Chem., 282, 34850-34857.

17 Kim EJ, Sung JY, Lee HJ, Rhim H, Hasegawa M, Iwatsubo T, Min dS, Kim J, Paik SR \& Chung KC (2006) Dyrk1A phosphorylates alpha-synuclein and enhances intracellular inclusion formation. J. Biol. Chem., 281, 33250-33257.

18 Ryoo SR, Cho HJ, Lee HW, Jeong HK, Radnaabazar C, Kim YS, Kim MJ, Son MY, Seo H, Chung SH \& Song WJ (2008) Dual-specificity tyrosine(Y)-phosphorylation regulated kinase 1A-mediated phosphorylation of amyloid precursor protein: evidence for a functional link between Down syndrome and Alzheimer's disease. J. Neurochem., 104, 1333-1344.

19 Sitz JH, Baumgärtel K, Hämmerle B, Papadopoulos C, Hekerman P, Tejedor FJ, Becker W \& Lutz B (2008) The Down syndrome candidate dual-specificity tyrosine phosphorylation-regulated kinase $1 \mathrm{~A}$ phosphorylates the neurodegeneration-related septin 4. Neuroscience, 157, 596-605.

20 Wegiel J, Dowjat K, Kaczmarski W, Kuchna I, Nowicki K, Frackowiak J, Mazur KB, Wegiel J, Silverman WP, Reisberg B, Deleon M, Wisniewski T, Gong CX, Liu F, Adayev T, Chen-Hwang MC \& Hwang YW (2008) The role of overexpressed DYRK1A protein in the early onset of neurofibrillary degeneration in Down syndrome. Acta Neuropathol., 116, 391-407.

21 Himpel S, Panzer P, Eirmbter K, Czajkowska H, Sayed M, Packman LC, Blundell T, Kentrup H, Grotzinger J, Joost HG \& Becker W (2001) Identification of the autophosphorylation sites and characterization of their effects in the protein kinase DYRK1A. Biochem. J., 359, 497-505.

22 Lochhead PA, Sibbet G, Kinstrie R, Cleghon T, Rylatt M, Morrison DK \& Cleghon V (2003) dDYRK2: a novel dual-specificity tyrosine-phosphorylation-regulated kinase in Drosophila. Biochem. J., 374, 381-391.

23 Lochhead PA, Sibbet G, Morrice N \& Cleghon V (2005) Activation-loop autophosphorylation is mediated by a novel transitional intermediate form of DYRKs. Cell, 121, 925-936.

24 Adayev T, Chen-Hwang MC, Murakami N, Lee E, Bolton DC \& Hwang YW (2007) Dualspecificity tyrosine phosphorylation-regulated kinase $1 \mathrm{~A}$ does not require tyrosine phosphorylation for activity in vitro. Biochemistry, 46, 7614-7624.

25 Bain J, McLauchlan H, Elliott M \& Cohen P (2003) The specificities of protein kinase inhibitors: an update. Biochem. J., 371, 199-204.

26 Kim ND, Yoon J, Kim JH, Lee JT, Chon YS, Hwang MK, Ha I \& Song WJ (2006) Putative therapeutic agents for the learning and memory deficits of people with Down syndrome. Bioorg. Med. Chem. Lett., 16, 3772-3776.

27 Koo KA, Kim ND, Chon YS, Jung MS, Lee BJ, Kim JH \& Song WJ (2009) QSAR analysis of pyrazolidine-3,5-diones derivatives as Dyrk1A inhibitors. Bioorg. Med. Chem. Lett., $19,2324-2328$.

28 Bain J, Plater L, Elliott M, Shpiro N, Hastie CJ, McLauchlan H, Klevernic I, Arthur JS, Alessi DR \& Cohen $P(2007)$ The selectivity of protein kinase inhibitors: a further update. Biochem. J., 408, 297-315.

29 Guedj F, Sébrié C, Rivals I, Ledru A, Paly E, Bizot JC, Smith D, Rubin E, Gillet B, Arbones M \& Delabar JM (2009) Green tea polyphenols rescue of brain defects induced by overexpression of DYRK1A. PLOS ONE, 4:e4606.

30 Lambert JD, Lee MJ, Lu H, Meng X, Hong JJ, Seril DN, Sturgill MG \& Yang CS (2003) Epigallocatechin-3-gallate is absorbed but extensively glucuronidated following oral administration to mice. J. Nutr. 133, 4172-4177. 
31 Yang CS, Sang S, Lambert JD \& Lee MJ (2008) Bioavailability issues in studying the health effects of plant polyphenolic compounds. Mol. Nutr. Food Res., 52 Suppl $1: S 139-151$.

32 Kim H, Sablin SO \& Ramsay RR (1997) Inhibition of monoamine oxidase A by betacarboline derivatives. Arch. Biochem. Biophys., 337, 137-142.

33 Song Y, Kesuma D, Wang J, Deng Y, Duan J, Wang JH \& Qi RZ (2004) Specific inhibition of cyclin-dependent kinases and cell proliferation by harmine. Biochem. Biophys. Res. Commun., 317, 128-132.

34 de Graaf K, Czajkowska H, Rottmann S, Packman LC, Lilischkis R, Lüscher B \& Becker W (2006) The protein kinase DYRK1A phosphorylates the splicing factor SF3b1/SAP155 at Thr434, a novel in vivo phosphorylation site. BMC Biochem., 7, 7.

35 Shimizu Y, Kanamori T \& Ueda T (2005) Protein synthesis by pure translation systems. Methods, 36, 299-304.

36 Laguna A, Aranda S, Barallobre MJ, Barhoum R, Fernandez E, Fotaki V, Delabar JM, de la LS, de I, V \& Arbones ML (2008) The protein kinase DYRK1A regulates caspase-9mediated apoptosis during retina development. Dev. Cell, 15, 841-853.

37 Seifert A, Allan LA \& Clarke PR (2008) DYRK1A phosphorylates caspase 9 at an inhibitory site and is potently inhibited in human cells by harmine. FEBS J., 275, 62686280.

38 Kuhn C, Frank D, Will R, Jaschinski C, Frauen R, Katus HA \& Frey N (2009) DYRK1A is a novel negative regulator of cardiomyocyte hypertrophy. J. Biol. Chem. 284, 1732017327.

39 Waki H, Park KW, Mitro N, Pei L, Damoiseaux R, Wilpitz DC, Reue K, Saez E \& Tontonoz $P(2007)$ The small molecule harmine is an antidiabetic cell-type-specific regulator of PPARgamma expression. Cell Metab, 5, 357-370.

40 Callaway JC, McKenna DJ, Grob CS, Brito GS, Raymon LP, Poland RE, Andrade EN, Andrade EO \& Mash DC (1999) Pharmacokinetics of Hoasca alkaloids in healthy humans. J. Ethnopharmacol., 65, 243-256.

41 Lewin L (1929) Banisteria Caapi - ein neues Rauschgift und Heilmittel. Georg Stilke, Berlin.

42 Branchi I, Bichler Z, Minghetti L, Delabar JM, Malchiodi-Albedi F, Gonzalez MC, Chettouh Z, Nicolini A, Chabert C, Smith DJ, Rubin EM, Migliore-Samour D \& Alleva E (2004) Transgenic mouse in vivo library of human Down syndrome critical region 1: association between DYRK1A overexpression, brain development abnormalities, and cell cycle protein alteration. J. Neuropathol. Exp. Neurol., 63, 429-440.

43 Liu T, Sims D \& Baum B (2009) Parallel RNAi screens across different cell lines identify generic and cell type-specific regulators of actin organization and cell morphology. Genome Biol., 10, R26.

44 Leder S, Weber Y, Altafaj X, Estivill X, Joost HG \& Becker W (1999) Cloning and characterization of DYRK1B, a novel member of the DYRK family of protein kinases. Biochem. Biophys. Res. Commun., 254, 474-479.

45 Becker W, Weber Y, Wetzel K, Eirmbter K, Tejedor FJ, Joost HG (1998) Sequence characteristics, subcellular localization, and substrate specificity of DYRK-related kinases, a novel family of dual specificity protein kinases. J. Biol Chem. 273, 2589325902.

46 Goslin K, Asmussen H \& Banker G (1998) Rat hippocampal neurons in low-densitiy culture. In Culturing Nerve Cells (Banker G \& Goslin K, eds), pp. 339-370. MIT Press, Cambridge. 


\section{Figure Legends}

Fig. 1. Inhibition of DYRK family kinases by harmine.
A, The structure of harmine
B, The relationship of mammalian DYRK kinases according to the sequence similarity in the catalytic domain. Percent values indicate the sequence identity between different family members.
C and $\mathbf{D}$, Recombinant kinases were incubated with the substrate peptide DYRKtide in the presence of different harmine concentrations and $100 \mu \mathrm{M}$ ATP. The data were analyzed using the GraphPad Prism 5 program and fitted to a "dose-response curve - inhibition" with a Hill slope of -1 or a variable slope if the Hill slope was significantly different from -1 (Table 1). Results are presented as means $+/$ - SEM, $(n=3-5$ or $n=2-$ 4 for DYRK4).

Fig. 2. Cytotoxicity of harmine.

A, Concentration-response curves. - Proliferating HEK293 cells or HeLa cells were incubated with variable concentrations of harmine for $56 \mathrm{~h}$. Cell viability was determined as the capacity of the cells to reduce WST-1 and normalized to that of untreated cells. The graphs summarize the results of three independent experiments (means +/- SEM).

B, Time course. - HeLa cells were treated for variable times with the indicated concentrations of harmine before the WST-1 reagent was added.

C, Real-time monitoring of harmine cytotoxicity.- Impedance measurement for determination of cell growth were converted to a cell index and normalized to the time point where harmine was added. Curves represent means of triplicate wells. In order 
to present the results more clearly, error bars for the S.D. are not shown for time points $<20 \mathrm{~h}$.

Fig. 3. Harmine inhibits SF3B1 phosphorylation by DYRK1A in HeLa cells. HeLa cells were transfected with pEGFP-SF3B1-NT plasmids and treated with harmine for 48 hours. Two days after transfection, phosphorylation of SF3B1 was determined by immunoblotting with an anti-pThr434 antibody, and the results were normalized to the total amount of SF3B1 immunoreactivity.
A, Representative Western blot.
B, Quantitative evaluation. The diagram presents the results of three independent experiments as the means of normalized pThr434 immunoreactivity relative to that in untreated cells +/- SEM.

Fig. 4. Harmine does not inhibit tyrosine autophosphorylation of DYRK1A in HEK293 $\underline{\text { cells }}$

A, HEK293-GFP-DYRK1A cells were stimulated with doxycycline and treated with harmine as indicated. Native lysates were subjected to immunoprecipitation with anti GFP antibody. DYRK1A phosphorylation was analyzed by immunoblotting with a phosphotyrosine-specific antibody (P-Tyr). The left panel shows Western blots of a representative experiment, while the right panel shows the quantitative evaluation of 3 experiments (means +/- SEM). The signal intensities of P-Tyr immunoreactivity were normalised to the anti GFP signal. The difference between the control and the harmine treated groups was not statistically significant (Student's $t$ test, $p=0.09$ ).

B, Aliquots of the cell lysates were analyzed for phosphorylation of endogenous SF3B1 at Thr434 to confirm the efficacy of the harmine treatment. 
C, Kinase activity of precipitated GFP-DYRK1A was determined by in vitro assays with DYRKtide and normalized to GFP immunoreactivity. The difference in activity between DYRK1A from the control and the harmine treated cells was not statistically significant (Student's $t$ test, $\mathrm{p}=0.09$ ). Columns and error bars represent means $+/-$ SEM from 3 experiments.

\section{Fig. 5. In vitro translation of DYRK1A in wheat germ extract}

FLAG-DYRK1A was translated in wheat germ extract in the presence of different concentrations of harmine or purvalanol A as indicated. The translated kinase was immunoprecipitated with anti-FLAG antibody and subjected to Western blot analysis with a phosphotyrosine-specific antibody (P-Tyr). Panel A shows Western blots from a representative experiment. Panel $\mathbf{B}$ shows the quantitative evaluation of 3 experiments (means +/- SEM). Signal intensities of phosphotyrosine immunoreactivity were normalized to the anti-DYRK1A signal. Panel $\mathbf{C}$ shows the kinase activity of precipitated kinase as determined by in vitro assay with DYRKtide. The activities were normalized to DYRK1A immunoreactivity.

Fig. 6. Effect of harmine on DYRK1A tyrosine autophosphorylation in an E. coliderived in vitro-translation system.

A, DYRK1Acat was transcribed and translated in a reconstituted E. coli system in the presence of recombinant SF3B1-NT. Aliquots of the reaction mixture were taken at the times indicated and subjected to Western blot analysis. SF3B1-NT was gradually degraded during course of the experiment. The band labelled by the asterisk ( $\left.{ }^{*}\right)$ is probably a transient degradation product of SF3B1. The hash key (\#) marks an unidentified band. 
B, DYRK1Acat was in vitro translated in the presence of the indicated concentrations of harmine. The reactions were run for $2 \mathrm{~h}$ before the immunoblot analysis. Western blots of a representative experiment are shown in the upper panels. For quantitative evaluation, the signal intensities of phosphotyrosine immunoreactivity were normalized to the anti DYRK1A signal. The graph summarizes the data from three independent experiments (means +/- S.D.). The data were analyzed by nonlinear curve fitting $\left(\mathrm{IC}_{50}=1.80 \mu \mathrm{M}, 95 \%\right.$ confidence interval 0.34-9.62 $\left.\mu \mathrm{M}\right)$.

Fig. 7. Effect of harmine on neurite formation in hippocampal neurons.

Hippocampal neurons were cultured for three days in the presence or absence (control) of $1.6 \mu \mathrm{M}$ harmine. A, Graphical representation of the data of three independent experiments. No neurons were found with less than two or more than six neurites. The columns represent means \pm S.D. from three independent experiments. Student's $t$ test analysis was applied to each pair of control and harmine treated data. B,C, Images of representative neurons immunostained with anti- $\beta 3$ tubulin antiserum from control and harmine treated cultures, exhibiting four and three neurites, respectively. 


\section{Tables}

Table 1 Quantitative analysis of the data presented in Fig. 1

\begin{tabular}{lrrrr} 
Kinase & $I C_{50}[\mathrm{nM}]$ & $\begin{array}{c}95 \% \text { confidence } \\
\text { interval, } I C_{50}[\mathrm{nM}]\end{array}$ & $\begin{array}{c}\text { Goodness of fit } \\
\left(R^{2}\right)\end{array}$ & Hill slope \\
\hline DYRK1A & 33 & $26-42$ & 0.977 & $-0.662^{\mathrm{a}}$ \\
DYRK1B & 166 & $133-205$ & 0.970 & -1 \\
MNB & 149 & $128-175$ & 0.982 & -1 \\
DYRK2 & 1,931 & $1,197-3,115$ & 0.881 & -1 \\
DYRK4 & 79,750 & $39,780-159,900$ & 0.842 & $-0.405^{\mathrm{a}}$
\end{tabular}

a, significantly different from -1 (extra sum of squares $F$ test, $p<0.05$ ) 

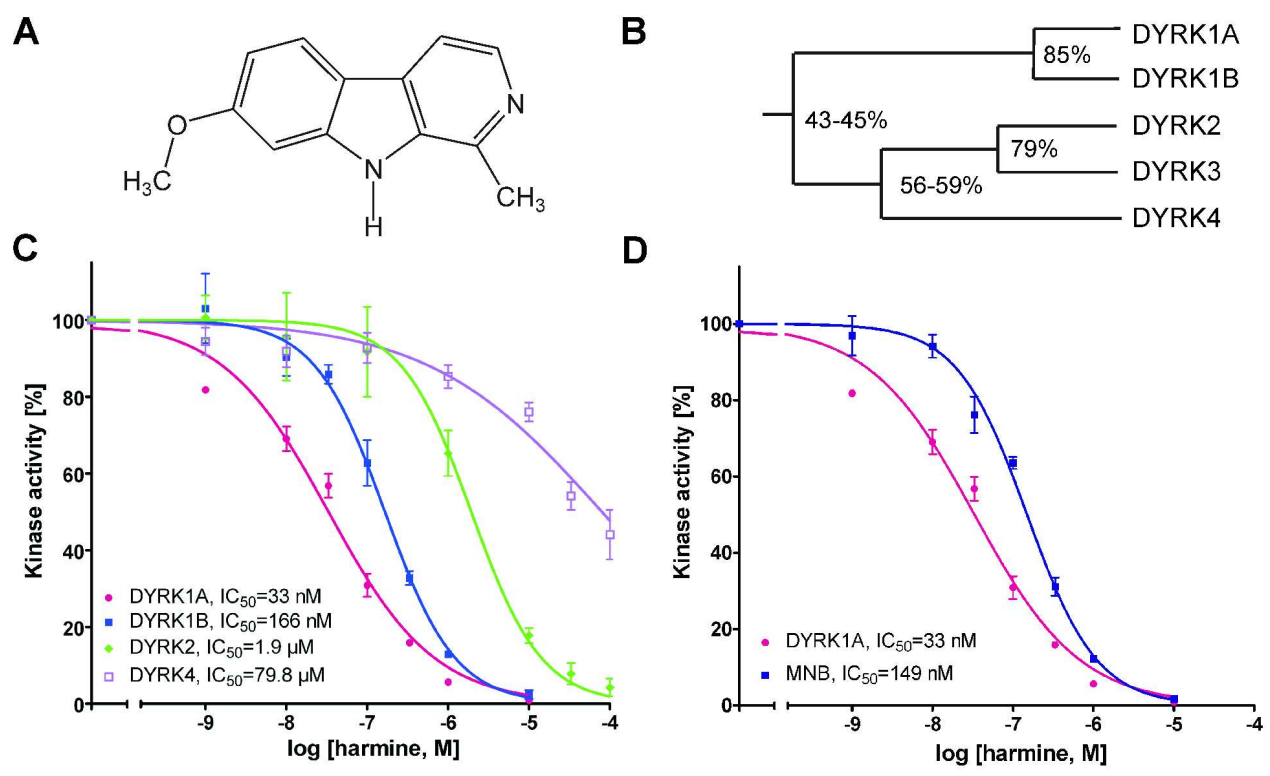

Figure 1 Göckler et al. 
Page 33 of 38

FEBS Journal

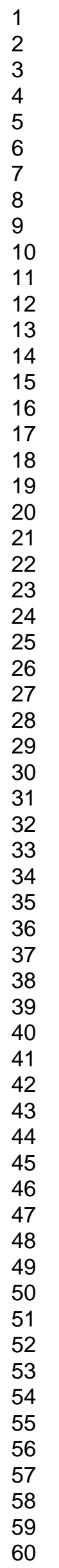
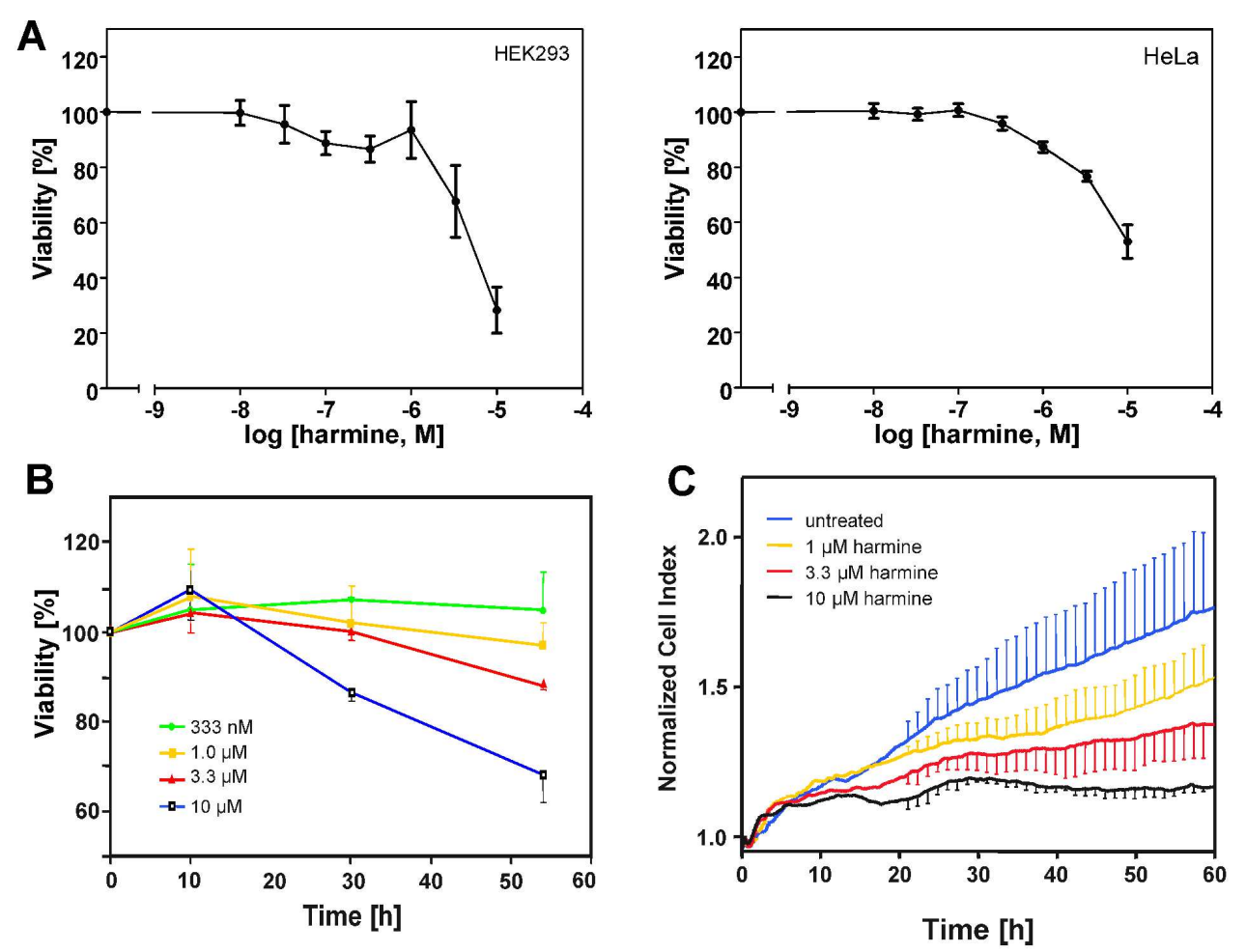

Figure 2 Göckler et al. 


\section{A}

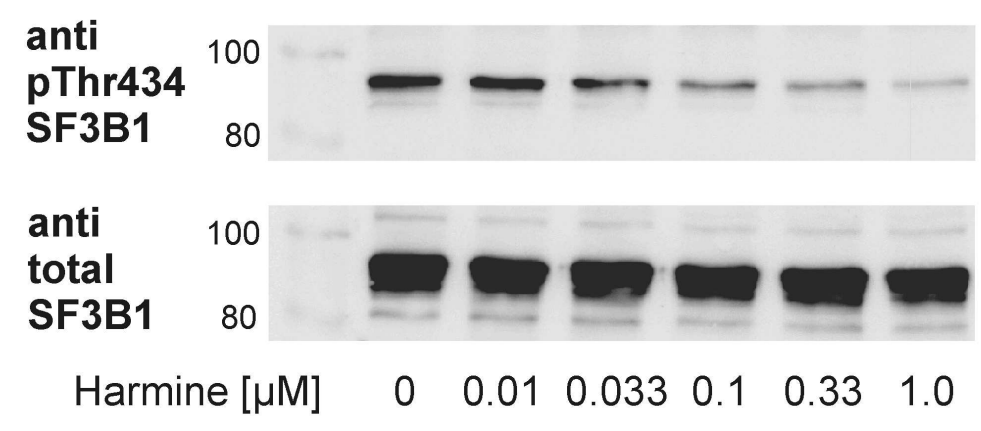

B

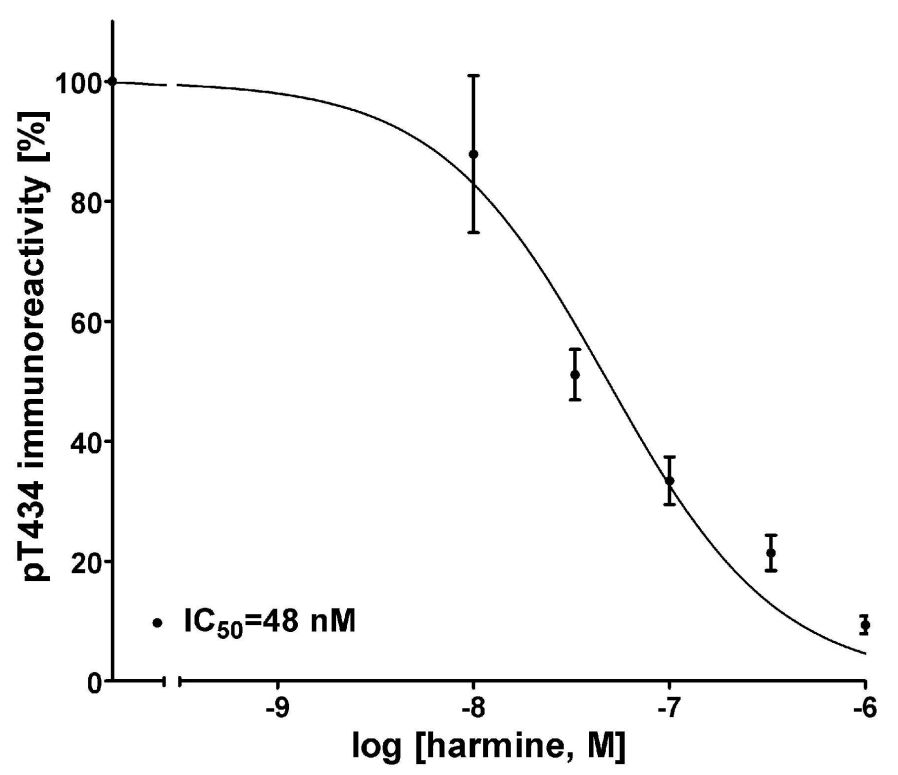

Figure 3 Göckler et al. 


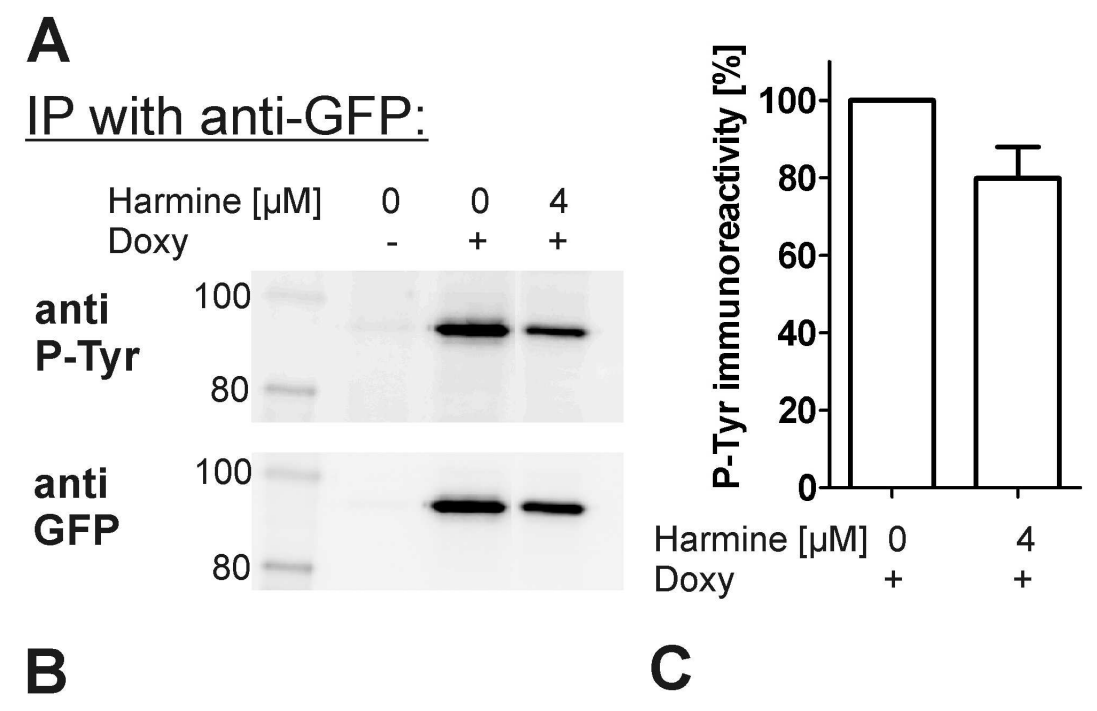

Total cell lysates:

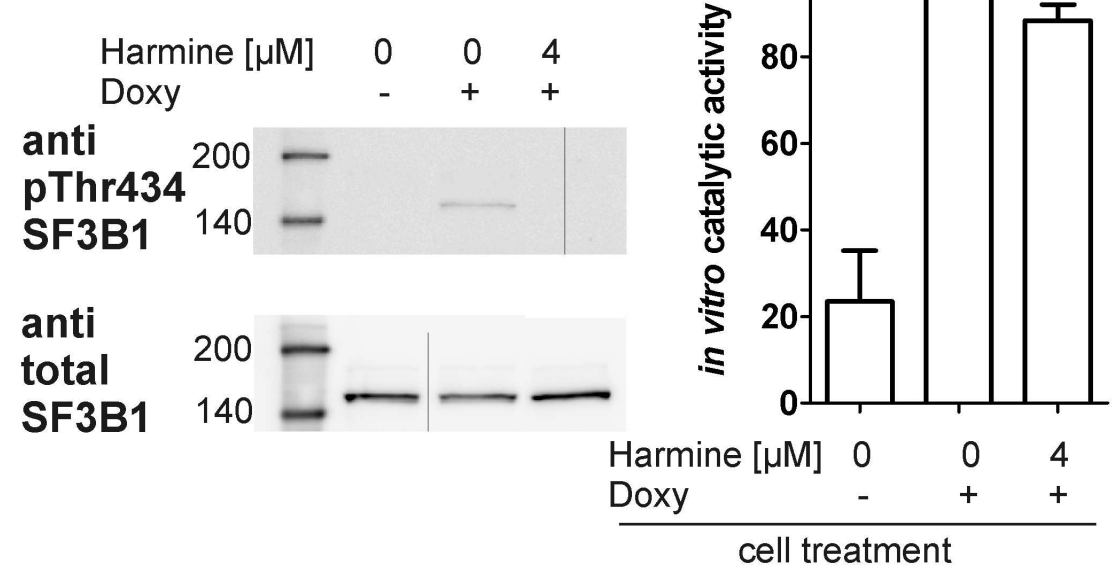

Figure 4 Göckler et al. 
A

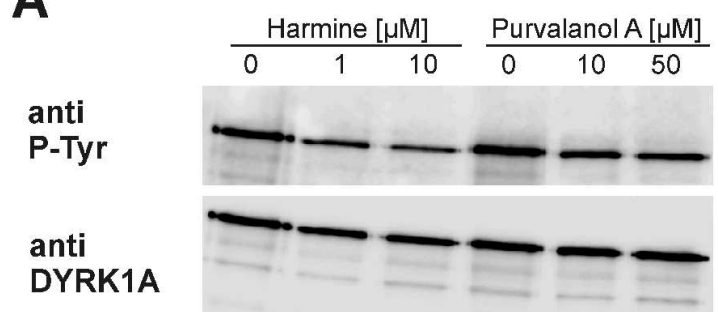

B

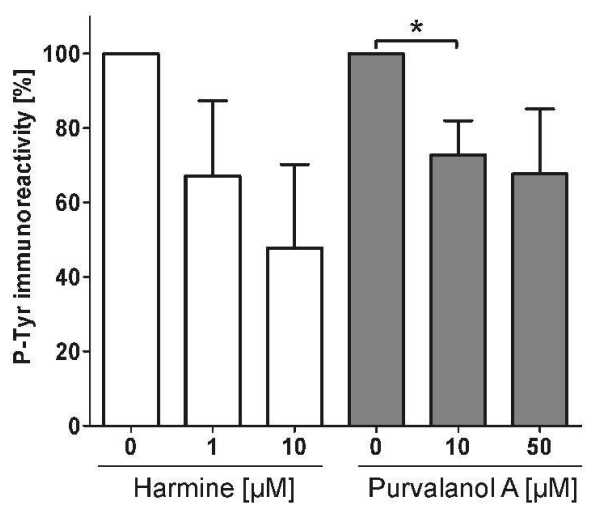

C

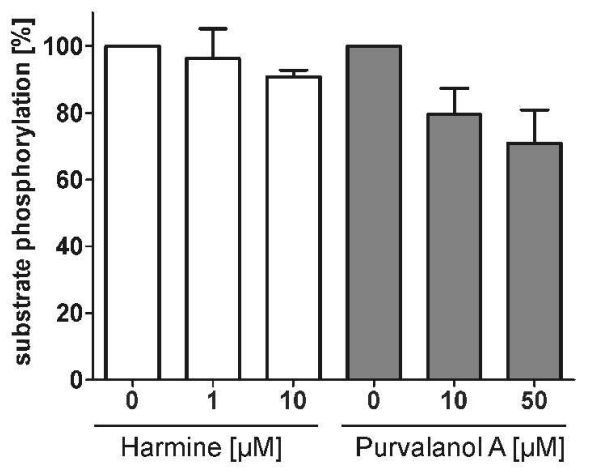

Figure 5 Göckler et al. 
A

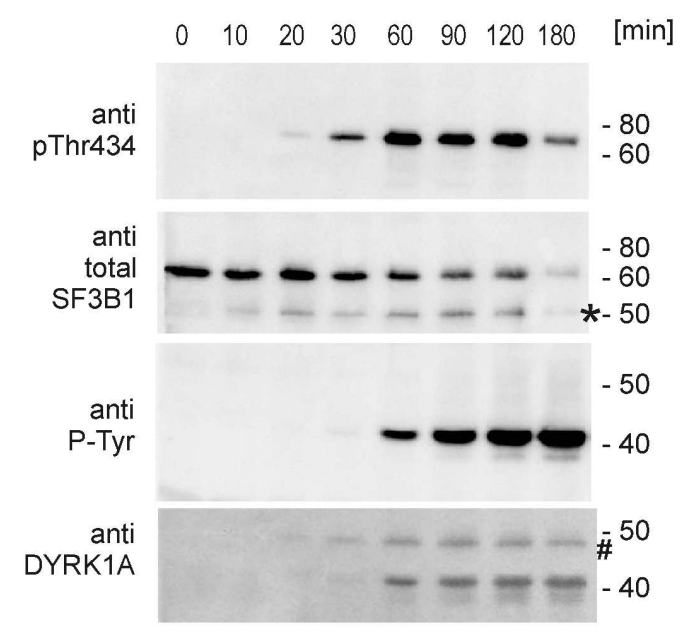

Figure 6 Göckler et al.
B
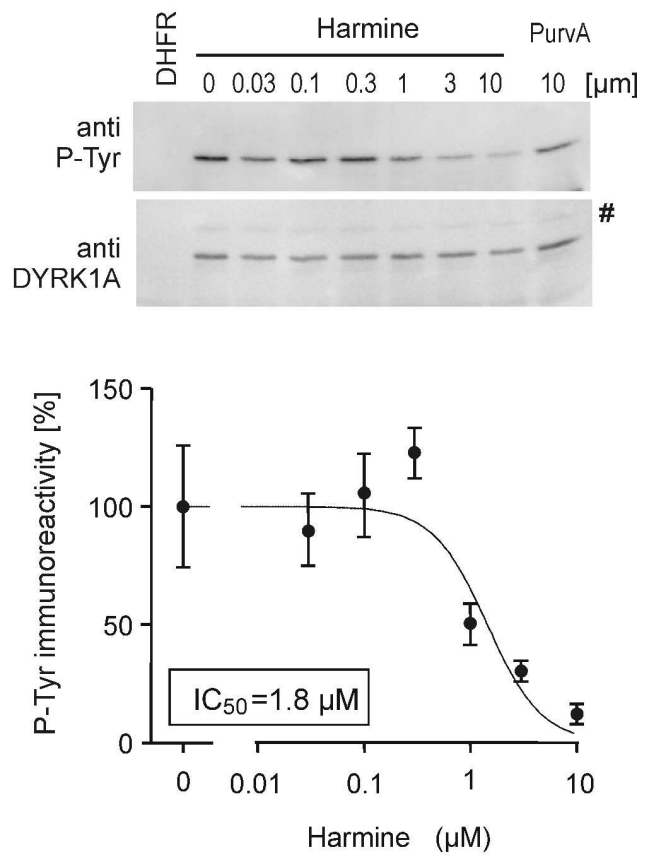


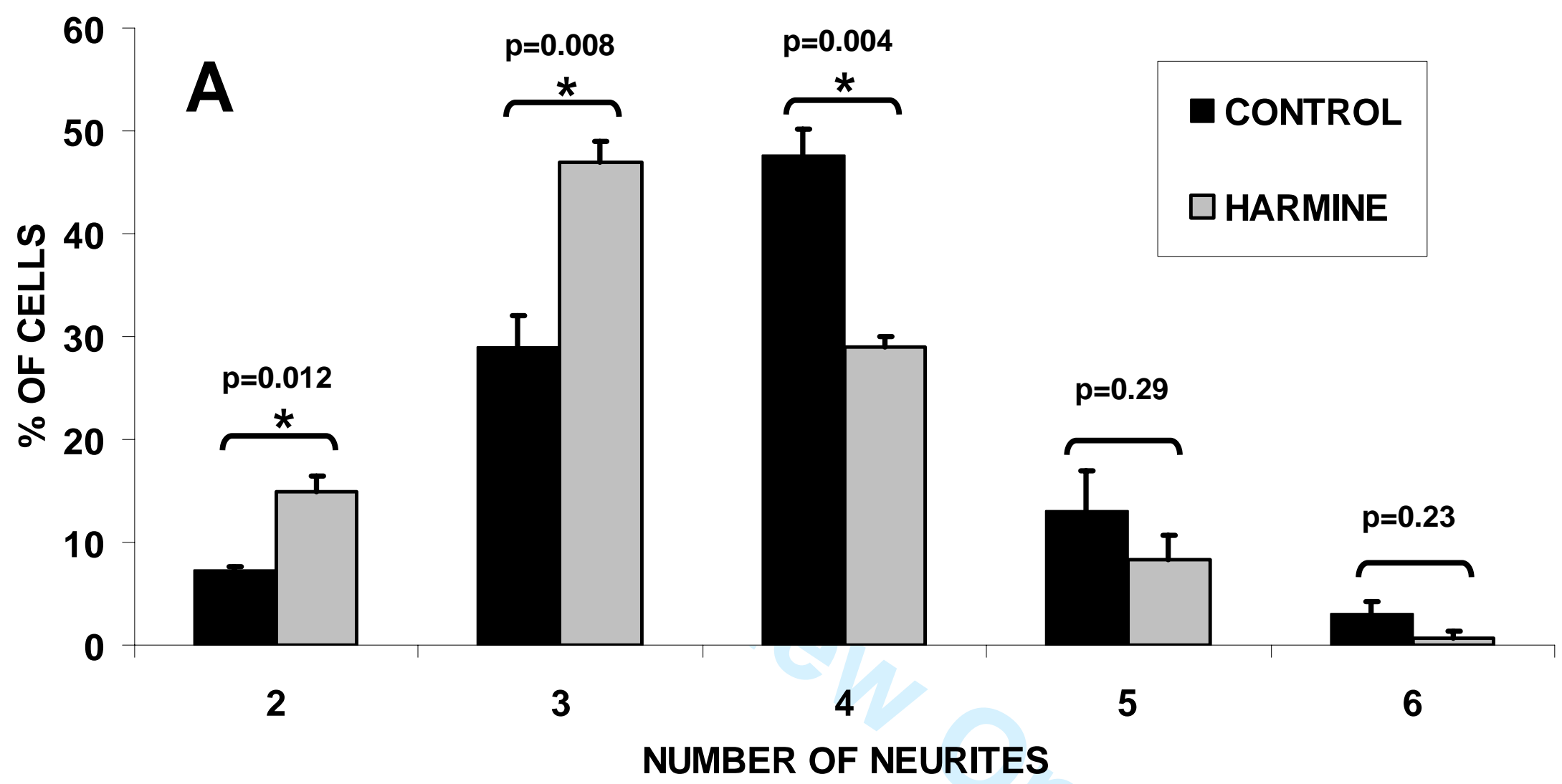

B

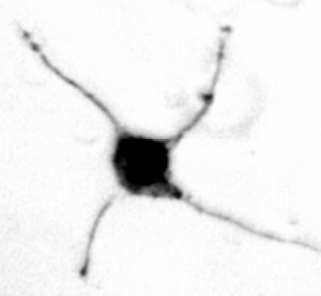

$25 \mu \mathrm{m}$ 